\title{
Improving Patient-Clinician Conversations During Annual Wellness Visits
}

\author{
Zsolt J. Nagykaldi, PhD, Ami Dave, MS3, Connor J. Kristof, MS3, \\ Tanya N. Watts, MS4, Sravanthi Utpala, MD, and Elizabeth Wickersham, MD
}

Background: Health risk assessments (HRAs) have been implemented and studied for decades in various settings, but little is known about the effect of introducing HRAs on the dynamics and content of patient-clinician conversations during Medicare Annual Wellness Visits (AWVs) and whether the effective use of HRAs requires additional training and resources.

Methods: We used Conversation Analysis techniques to analyze $40 \mathrm{AWVs}$ conducted in an academic family medicine residency practice. After a 3-month baseline period, a low-intensity intervention was implemented to explore improvements in the dynamics and content of conversations. Short exit interviews with patients and clinicians were evaluated by standard content analytic techniques.

Results: Six overarching themes emerged that described the dynamics of AWV conversations. Patients and clinicians sub-optimally utilized the HRA report and missed many opportunities for promoting behavior change. However, a low-intensity, multi-component intervention significantly decreased the proportion of clinician talk time per visit by $9 \%(P<.001)$, while it increased the proportion of patient talk time by $7 \%$ $(P<.001)$, robustly increased the number and duration of "change talk" by $639 \%(P=.0007)$, increased the number of patient cut-ins by $237 \%(P=.04)$ and tended to increase the number and duration of clinician "advice talk" $(P=.065)$. Patients felt more informed, empowered, and motivated by the HRA-enhanced wellness visit. Clinicians found that the process helped them construct a more effective visit agenda and it facilitated the convergence of patient goals with evidence-based recommendations.

Conclusions: Our study suggests that HRAs introduced without proper framing, education, and additional resources may not allow patients and clinicians to leverage AWVs for effective health planning and improvement. A targeted, low-intensity intervention may help patients and clinicians improve the quality of HRA-guided health conversations during AWVs. (J Am Board Fam Med 2017;30:161-169.)

Keywords: Annual Wellness Visit, Conversation Analysis, Health Risk Appraisal, Patient Goals, Primary Health Care

The Patient Protection and Affordable Care Act of 2010 (ACA) instituted annual wellness visits (AWVs) and implemented a new payment structure for Medicare AWVs. ${ }^{1}$ Payment for AWVs has been tied to addressing specific clinical content and implementing a health risk assessment (HRA) that covers 34 required elements, including demographics, health status, psychosocial and behavioral risk factors, activities/instrumental activities of daily living, and the development of a personalized health plan. ${ }^{2}$ When the ACA incorporated systematic financial support for longitudinal health planning and prevention in AWVs, it created a long-awaited opportunity for primary care practices to more ef-

This article was externally peer reviewed.

Submitted 18 July 2016; revised 26 September 2016; accepted 3 October 2016. fectively align their mission (improving the health and well-being of a community) with the sustainability of their organization. Although payment for Medicare AWVs is a step in the right direction, much work needs to be done to identify and test effective approaches to implementing AWVs in community settings.

There are many gaps in our knowledge pertaining to the role and effective participation of patients in AWVs, the types and specific content of HRAs that may improve process and health outcomes, how AWVs should be structured, what re-

From the Department of Family and Preventive Medicine, University of Oklahoma Health Sciences Center, Oklahoma City.

Funding: This study received intramural support from the University of Oklahoma Health Sciences Center Department of Family Medicine. 
sources and education clinicians and practice staff might need to make AWVs effective, how patients can be empowered to meaningfully participate, what personalized wellness plans should include and how these plans can be communicated to others, how wellness plans and care goals can be documented in a problem-oriented medical record, how practices can efficiently and appropriately respond to complex behavioral health needs emerging from AWVs, and how systematic patient follow-up can be provided to reach the goals set in AWVs. In this pilot study, which was part of a medical student research experience program, our team aimed to bridge some of these gaps by observing, analyzing, and improving HRA-based health planning conversations in primary care settings.

\section{Methods}

Three medical students (AD, CK, TW) and an MD graduate $(\mathrm{SU})$ were trained as research assistants (RAs). They obtained consent from 5 physician faculty, working in 3 residency practices of the University of Oklahoma Department of Family and Preventive Medicine, to participate in an study of AWVs from April through July 2015. The RAs reviewed the electronic medical records of patients who were scheduled for an AWV and applied a set of inclusion/exclusion criteria. Inclusion criteria included being established in the practice (at least 2 visits in the past 12 months), a health status that allows participation in the study, and age $\leq 85$ years (to ensure that there is a tangible benefit from general preventive services). Patients were excluded if they were institutionalized, they had a level of cognitive impairment that prohibited the provision of informed consent, or they were so overwhelmed by acute medical problems that it was difficult to focus on preventive care. Preliminary lists were compiled for each physician to ensure that patients who were no longer in the practice or could not benefit from participation were removed. The RAs invited eligible patients via phone (using a standardized call script) to participate at the time of

Conflict of interest: none declared.

Corresponding author: Zsolt J. Nagykaldi, PhD, Department of Family and Preventive Medicine, University of Oklahoma Health Sciences Center, 900 NE 10th St, Oklahoma City, OK 73104 (E-mail: znagykal@ouhsc.edu). their scheduled AWV and briefly explained the project to obtain verbal consent.

The RAs then administered a signed, informed consent to 40 distinct patients in the waiting room and assisted them to complete a validated, Webbased HRA tool, ${ }^{3}$ which our team developed and implemented before the study, via a touch-screen enabled, handheld computer or a desktop computer set up on a cart. The complete HRA covered all 34 elements required by the Centers for Medicare and Medicaid Services Final Rule. The completion of the Web-based HRA took about 20 minutes for most participants. Patients who agreed to participate were asked to arrive about 30 minutes before their original appointment time to complete the HRA and other, study-related data collection steps. In addition to office-based completion, patients could also complete the HRA online, before they came to the office. At the end of the HRA, a tailored health planner report was printed and given to the patient to review briefly before the physician entered the examination room. The patient and his or her physician then discussed the HRA report during the visit and agreed on a personalized wellness plan based on the report. Although the HRA and the report were saved electronically for future AWVs, patients were asked to keep the HRA report as part of their records.

About 30 days before the end of the study, 3 of the participating clinicians and their AWV patients were selected to receive a low-intensity educational intervention. Clinicians received a 30-minute, high-quality, Web-based introduction to motivational interviewing (MI) and collaborative goal setting, a 15-minute orientation on the HRA report and how it can be used for health planning, and a 1-page MI administration aid that was adapted from an existing tool used in pediatric settings. ${ }^{4}$ Clinicians also received coding support to help them optimize reimbursement for AWVs and avoid triggering additional unnecessary patient co-pays. Patients received a 5 -minute orientation by the RA before the visit to help them think about their health priorities and more effectively communicate with their physician about the HRA report. AWVs were respectfully recorded using professionally installed video equipment that our academic program has been using routinely for resident education. ${ }^{5}$ The cameras were angled so that they showed only the consultation area of the examination room, excluding the examination table. Patients explicitly 
agreed to the recording in writing and also verbally at the time of the visit. They also had the option to ask the physician to terminate the recording at any time during the visit. The RAs followed the visits on a privately placed, small video screen and listened to the conversation through a headset to make observations and to start or stop the recording as necessary. Participating physicians were accustomed to the camera and often seemed oblivious to being recorded because of the routine use of the equipment during medical training.

To analyze recordings, we leveraged a conversation analysis (CA) approach, ${ }^{6,7}$ which helped us derive themes and categories incrementally from each visit that characterized the dynamics of the encounter, participation of the actors, communication content and modalities, and the effectiveness of the shared decision-making and goal-setting process. CA includes the following steps: (1) selecting a sequence of interest in the recording-in our case, the entire recorded sequence; (2) characterizing the actions seen in the sequence; (3) considering how the speakers package their message or their mode of action; (4) measuring the time of various actions or turns taken in conversations; and (5) observing the ways the actions are accomplished and how actions may affect shared decision making. At least 2 evaluators reviewed each AWV recording on a computer and carefully coded them in 30second segments. Intercoder reliability was enhanced by training all evaluators together, followed by group coding exercises, discussing segments of several AWVs, and arguing them to consensus. Coders used a standardized Excel database to record their observations. Qualitative notations were recorded in an "actions table" that allowed the coders to characterize the communication and describe how messages were packaged, what the potential implications of the communication might be pertaining to shared decision making and goal setting, and which talk category the communication represented. A note field was also available to record other observations and thoughts about each segment. The coders then reviewed each recording again to conduct a "turns analysis." They separated the AWV into natural conversation units, or turns (periods when a participant "has the ball"), and examined them to determine how the turn was initiated (question, response, initiation of a new topic, or rapid-exchange communication), who was speaking (patient, clinician, other), how long they spoke, and whether they cut into each other's talk. Representative samples of actions and turns analyses are shown in Tables 1 and 2. The entire process of scheduling, recording, and analyzing AWVs was "beta-tested" and iteratively improved during 5 wellness visits in a separate clinician practice before data collection was initiated.

To address some of the limitations of the quasiexperimental design of the pilot study, 22 recordings from before and after the intervention were carefully matched on known covariates, including the clinician, clinic location, visit duration, patient demographics, and the number of conversational turns per visit (Table 3). This subset of recordings was then explored separately by 3 evaluators $(\mathrm{AD}$, $\mathrm{SU}, \mathrm{ZN}$ ) using CA techniques to describe the dynamics and content of patient-clinician conversations in an integrated-methods framework. Short exit interviews with patients and clinicians were evaluated by standard content analytic techniques that included consensus-based development of codes and iterative formation of themes. Recordings and exit interviews were supplemented by RA field notes about the general process of care, the practice workflow, and administrative information to better understand the setting and circumstances of findings.

As a representation of emerging themes, the analytic team, which consisted of a faculty mentor (ZJ) and the 4 RAs, constructed a conceptual model to represent and summarize findings from recordings and draw conclusions pertaining to health-planning conversations.

All digital recordings were collected and kept securely on DVDs in a locked research data room in the Department of Family and Preventive Medicine Research Division. Only the RAs and the mentor had access to the recordings and dedicated computers in the same room to review and analyze patient visits. Deidentified data were kept in controlled-access file repositories.

Quantitative data (frequencies and proportions) were analyzed using Fisher's exact test or MannWhitney $U$ test, as appropriate. The study was approved by the University of Oklahoma Institutional Review Board.

\section{Results}

The 40 patient participants reflected the group of AWV patients seen by faculty with regard to most covariates. The average age was 53 years, $72 \%$ were 
Table 1. Conversation Analysis Example Including Coded Actions from a Segment of an Annual Wellness Visit

\begin{tabular}{|c|c|c|c|c|}
\hline $\begin{array}{l}\text { Time Anchor } \\
\text { (Time Stamp) }\end{array}$ & $\begin{array}{l}\text { Characterization of Action } \\
\text { (What Is Accomplished } \\
\text { via Communication) }\end{array}$ & $\begin{array}{c}\text { Packaging of Action (How } \\
\text { Messages Are } \\
\text { Communicated) }\end{array}$ & $\begin{array}{l}\text { Potential Implications } \\
\text { of Action (Impact on } \\
\text { Decision Making or } \\
\text { Goal Setting) }\end{array}$ & Talk Type \\
\hline $10: 00$ & $\begin{array}{l}\text { Doctor emphasizes that } \\
\text { smoking cessation will } \\
\text { give most health benefit } \\
\text { for this patient }\end{array}$ & $\begin{array}{l}\text { Professional authoritative } \\
\text { statements invoking } \\
\text { evidence }\end{array}$ & $\begin{array}{l}\text { Patient may be more } \\
\text { likely to take steps } \\
\text { to quit smoking } \\
\text { when the message } \\
\text { comes from the } \\
\text { doctor }\end{array}$ & Advice \\
\hline $10: 30$ & $\begin{array}{l}\text { Doctor asks how much } \\
\text { patient is smoking a day }\end{array}$ & $\begin{array}{l}\text { Respectful and tactful } \\
\text { initiation of topic }\end{array}$ & $\begin{array}{l}\text { Getting overall idea } \\
\text { of patient's desire } \\
\text { to quit, if any }\end{array}$ & \\
\hline 11:00 & $\begin{array}{l}\text { Patient says smoking } \\
\text { cessation is not a goal } \\
\text { for him currently; } \\
\text { doctor asks him to } \\
\text { elaborate }\end{array}$ & $\begin{array}{l}\text { Doctor uses motivational } \\
\text { interviewing techniques } \\
\text { to elicit thinking about } \\
\text { behavior }\end{array}$ & $\begin{array}{l}\text { Patient reflects on } \\
\text { why quitting } \\
\text { smoking is not a } \\
\text { current priority }\end{array}$ & $\begin{array}{l}\text { Change } \\
\text { talk }\end{array}$ \\
\hline $11: 30$ & $\begin{array}{l}\text { Patient inquires about } \\
\text { benefits of switching to } \\
\text { "healthier" cigarettes/ } \\
\text { vaping }\end{array}$ & $\begin{array}{l}\text { "I am not ready yet to } \\
\text { jump, but perhaps in } \\
\text { steps. .." }\end{array}$ & $\begin{array}{l}\text { Patient education and } \\
\text { moving patient } \\
\text { along the } \\
\text { continuum of } \\
\text { change }\end{array}$ & $\begin{array}{l}\text { Change } \\
\text { talk }\end{array}$ \\
\hline $12: 00$ & $\begin{array}{l}\text { Doctor explains research } \\
\text { findings, encourages } \\
\text { patient to make that } \\
\text { small change }\end{array}$ & $\begin{array}{l}\text { Skillful guidance in } \\
\text { synergy with authority }\end{array}$ & $\begin{array}{l}\text { Patient education, } \\
\text { encouragement to } \\
\text { take small steps } \\
\text { toward quitting } \\
\text { smoking (toward a } \\
\text { SMART goal) }\end{array}$ & $\begin{array}{l}\text { Change } \\
\text { talk }\end{array}$ \\
\hline $12: 30$ & $\begin{array}{l}\text { Doctor and patient talk } \\
\text { about increasing the } \\
\text { amount of sleep } \\
\text { prompted by HRA } \\
\text { recommendation }\end{array}$ & $\begin{array}{l}\text { Doctor "negotiates" with } \\
\text { patient about what a } \\
\text { reasonable goal would } \\
\text { be in terms of hours/ } \\
\text { night }\end{array}$ & $\begin{array}{l}\text { Goal setting; doctor } \\
\text { and patient agree } \\
\text { on } 6.5 \text { hours/night }\end{array}$ & $\begin{array}{l}\text { Goal } \\
\text { setting }\end{array}$ \\
\hline $13: 00$ & $\begin{array}{l}\text { Doctor encourages patient } \\
\text { to follow the links on } \\
\text { the wellness portal to } \\
\text { receive more education }\end{array}$ & $\begin{array}{l}\text { Effective "time-saving" } \\
\text { approach leveraging } \\
\text { technology/info patient } \\
\text { already has access to }\end{array}$ & $\begin{array}{l}\text { Patient may use } \\
\text { wellness portal } \\
\text { resources to make } \\
\text { more successful } \\
\text { lifestyle changes }\end{array}$ & Advice \\
\hline $13: 30$ & $\begin{array}{l}\text { Doctor and patient talk } \\
\text { about how to modify } \\
\text { response to stress in } \\
\text { patient's life }\end{array}$ & $\begin{array}{l}\text { Empathy and personal } \\
\text { reassurance of } \\
\text { understanding }\end{array}$ & $\begin{array}{l}\text { Patient is encouraged } \\
\text { to change response } \\
\text { to stress in an } \\
\text { understanding } \\
\text { environment }\end{array}$ & $\begin{array}{l}\text { Change } \\
\text { talk }\end{array}$ \\
\hline $14: 00$ & $\begin{array}{l}\text { Doctor makes } \\
\text { recommendations on } \\
\text { how to respond to } \\
\text { stress }\end{array}$ & Coaching/facilitative tone & $\begin{array}{l}\text { Patient receives } \\
\text { specific strategies } \\
\text { for coping with } \\
\text { stress }\end{array}$ & Advice \\
\hline
\end{tabular}

HRA, health risk assessment; SMART, Specific-Measurable-Achievable-Realistic-Time-Bound.

female, and $>50 \%$ were nonwhite. Half of the participants had $\geq 1$ chronic condition, and $17 \%$ had $\geq 3$ chronic conditions. On average, patients had 15 years of education, $30 \%$ indicated that they had a median household income of $\leq \$ 40,000,22 \%$ were current or former smokers, and $40 \%$ described themselves as sedentary or insufficiently active. The age of clinicians ranged from 35 to 63 years, with an average of 52 years, and $60 \%$ of them were female. Their time in practice ranged from 8 to 38 years, with an average of 27 years. The average duration of AWVs and total talk time per AWV were the same in the pre- and post-intervention groups: 24 and $15 \mathrm{~min}$ utes, respectively. Only $10 \%$ of patients completed the HRA at home or some other location, although about $20 \%$ of them told the RAs on the phone that they intended to complete it in advance.

Forty AWVs were recorded over the study period, and 6 overarching themes emerged that characterized the dynamics of $\mathrm{AWV}$ conversations: 
Table 2. Conversation Analysis Example Including Coded "Turns" from a Segment of an Annual Wellness Visit

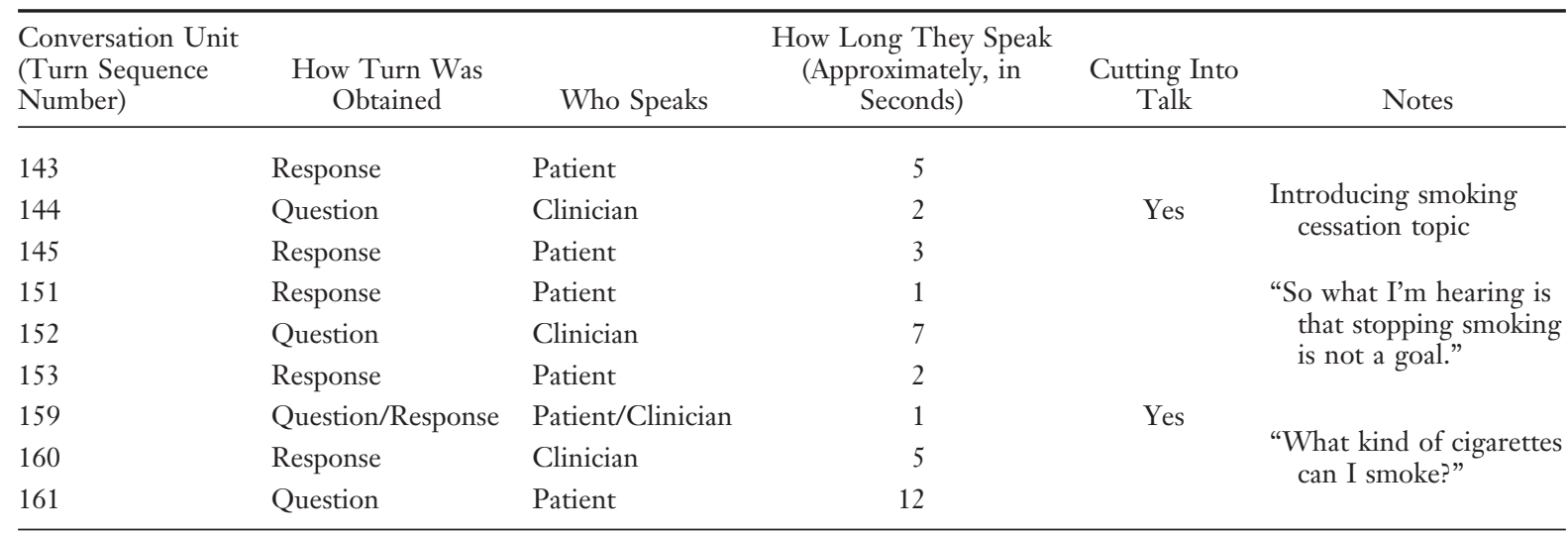

A "turn" is a natural conversation unit during which a specific speaker "has the ball."

communication, goals and focus, care delivery process, wellness plan barriers, patient experience, and readiness for change. As expected, the Communication domain related to both patients and clinicians. In the Patient subdomain, enabling and empowerment through education and resources were the main factors that seemed to influence the effectiveness of patient communication, whereas clinician communication was linked mainly to professional skills and experience. The Goals and Focus domain was characterized by the ability to participate in goal setting and focus on personalized care strategies. In that Patient subdomain, a sense of the purpose and framing of the AWVs (how they were different from regular, problem-focused visits) emerged as key factors. Proper framing of AWVs became a barrier for some patients without reorienting them toward planning for the future. Expected factors emerged from the Care Delivery Process domain, which was linked to facilitators and barriers of care provision, including patient factors (eg, level of health literacy, self-efficacy, trust) and systemic factors (eg, workflow, clinical pathways, insurance policies).

The analyses of AWV recordings also highlighted Wellness Plan Barriers, which included obstacles to creating a personalized wellness plan. This domain was linked to the ability of patients to leverage the HRA report (usability of technology and understanding the report), the clinician's access to resources (eg, clinical data or decision aids), and clinician skills to facilitate health planning. Patient Experience seemed to permeate every area of AWV conversations. Past experience with wellness visits and technology-aided decisionmaking support were particularly helpful. Because a substantial portion of HRA recommendations pertained to improving unhealthy behaviors, Readiness for Change emerged as a pivotal component of conversations that was able

Table 3. Characteristics of Covariates That Were Used to Match Annual Wellness Visits Before and After the Intervention

\begin{tabular}{|c|c|c|c|c|c|c|c|}
\hline Study Phase & $\begin{array}{l}\text { Clinicians and } \\
\text { Visits (n) }\end{array}$ & $\begin{array}{l}\text { Location of } \\
\text { Visits }\end{array}$ & $\begin{array}{l}\text { Talk Time } \\
\text { (seconds) }\end{array}$ & $\begin{array}{l}\text { Number of } \\
\text { Turns }\end{array}$ & $\begin{array}{l}\text { Patient Age } \\
\text { (years), } \\
\text { mean } \pm \text { SD }\end{array}$ & $\begin{array}{c}\text { Female patients } \\
(\%)\end{array}$ & $\begin{array}{c}\text { Nonwhite Race } \\
(\%)\end{array}$ \\
\hline \multirow{2}{*}{$\begin{array}{l}\text { AWVs before } \\
\text { intervention }\end{array}$} & Dr. A, 4 visits & Clinic A & 9976 (total) & 1179 (total) & \multirow[t]{2}{*}{$50 \pm 18$} & \multirow[t]{2}{*}{81} & \multirow[t]{2}{*}{45} \\
\hline & $\begin{array}{l}\text { Dr. B, } 2 \text { visits } \\
\text { Dr. C, } 5 \text { visits }\end{array}$ & $\begin{array}{l}\text { Clinic B } \\
\text { Clinic C }\end{array}$ & $\begin{array}{l}906 \pm 271 \\
\quad \text { (per visit) }\end{array}$ & $\begin{array}{l}107 \pm 57 \\
\quad \text { (per visit) }\end{array}$ & & & \\
\hline \multirow{2}{*}{$\begin{array}{l}\text { AWVs after } \\
\text { intervention }\end{array}$} & Dr. A, 4 visits & Clinic A & 9882 (total) & 1320 (total) & \multirow[t]{2}{*}{$54 \pm 13$} & \multirow[t]{2}{*}{72} & \multirow[t]{2}{*}{54} \\
\hline & $\begin{array}{l}\text { Dr. B, } 2 \text { visits } \\
\text { Dr. C, } 5 \text { visits }\end{array}$ & $\begin{array}{l}\text { Clinic B } \\
\text { Clinic C }\end{array}$ & $\begin{array}{l}898 \pm 395 \\
\quad \text { (per visit) }\end{array}$ & $\begin{array}{l}120 \pm 50 \\
\quad \text { (per visit) }\end{array}$ & & & \\
\hline Difference & NS & NS & NS & NS & NS & $\mathrm{NS}(P=.65)$ & $\mathrm{NS}(P=.69)$ \\
\hline
\end{tabular}

AWV, annual wellness visit; NS, not significant; SD, standard deviation. 
Table 4. Explanations of Five Notable "Talk Types" Derived from Patient-Clinician Conversations Recorded During Annual Wellness Visits

\begin{tabular}{|c|c|c|}
\hline $\begin{array}{l}\text { Annual Wellness Visit } \\
\text { Talk Type }\end{array}$ & Talk Type Definition & $\begin{array}{l}\text { Examples from Annual Wellness Visit } \\
\text { Recordings }\end{array}$ \\
\hline Change talk & $\begin{array}{l}\text { Verbalization of the intent of or strategies for } \\
\text { changing health behavior (by patient or } \\
\text { clinician) }\end{array}$ & $\begin{array}{l}\text { Patient: "Do you think it would be healthier if I } \\
\text { switched from cigarettes to vaping?" } \\
\text { Clinician: "Well, vaping still carries health } \\
\text { risks, but it may be a step for you in the right } \\
\text { direction." }\end{array}$ \\
\hline Goal-setting talk & $\begin{array}{l}\text { Discussion of specific (short or long-term) } \\
\text { goals for changing behavior (by patient or } \\
\text { clinician) }\end{array}$ & $\begin{array}{l}\text { Clinician: "So, what I am hearing is that you } \\
\text { could increase your sleep time by about an } \\
\text { hour, so you could sleep at least } 61 / 2 \text { hours } \\
\text { every night? Could you start maybe next } \\
\text { week?" } \\
\text { Patient: "Yes, I think I could do that." }\end{array}$ \\
\hline Education talk & $\begin{array}{l}\text { Providing more in-depth patient education } \\
\text { (eg, explaining mechanisms) }\end{array}$ & $\begin{array}{l}\text { Clinician: "Physical activity has been shown to } \\
\text { improve steadiness and balance by } \\
\text { strengthening our muscles and helping us } \\
\text { better feel our movements as we walk. This } \\
\text { can also help prevent falls." }\end{array}$ \\
\hline Advice talk & $\begin{array}{l}\text { Providing specific and focused suggestions or } \\
\text { recommendations (without further } \\
\text { explanation) }\end{array}$ & $\begin{array}{l}\text { Clinician: "I encourage you to do the things we } \\
\text { have discussed and you said you would do, so } \\
\text { we can get your blood sugar under control. I } \\
\text { am afraid that if we can't get your sugar } \\
\text { under control, you may have to go on } \\
\text { insulin." }\end{array}$ \\
\hline Prescriptive talk & $\begin{array}{l}\text { Clinicians simply tell patients what to do } \\
\text { without much discussion or explanation }\end{array}$ & $\begin{array}{l}\text { Clinician: "You really need to see the } \\
\text { nutritionist! When we are finished, I am } \\
\text { going to go ahead and put in a referral." } \\
\text { Clinician: "Your pneumonia shot is due today; I } \\
\text { will ask the nurse to give you the shot before } \\
\text { you leave." }\end{array}$ \\
\hline
\end{tabular}

to further shared decision making. Here, the level of patient activation and general attitudes toward behavior change emerged as important factors that influenced conversations.

Analyses of AWVs indicated that, at baseline, patients and clinicians suboptimally used the HRA report and missed many opportunities for shared decision making and behavior change. They also tended to drift away from general health conversations and health care planning and moved toward addressing specific clinical problems. Clinicians often dominated the conversation and set the agenda, and they frequently educated patients and provided salient advice. Time constraints (eg, starting an AWV when the clinician was already running behind) remained a significant barrier during the entire study. Periodically, both patients and clinicians seemed to struggle with the framing of the AWV and what its structure and content should be, compared with other types of office visits. Clinicians had variable skills to facilitate behavioral health conversations and effectively move conversations toward change. Based on the analyses of AWVs, the evaluators defined 5 notable "talk types," which are summarized in Table 4. During the baseline period, only $54 \%$ of AWVs included "change talk," which was defined as a clear verbalization of an intent or strategies for improving health behaviors either by the patient or the clinician. Only 1 of the 11 baseline visits included "goal-setting talk" (conversation about setting a Specific-MeasurableAchievable-Realistic-Time-bound goal ${ }^{8}$ to address a health issue). Other types of conversations included "education talk" (general patient education) and "prescriptive talk" (clinicians telling patients what to do), which occurred in $100 \%$ and $45 \%$ of visits, respectively.

The low-intensity intervention significantly decreased the proportion of clinician talk time per visit by $9 \%$ (from $45 \%$ to $41 \%$ of the total talk time; $P<.001$ ), while it increased the proportion of patient talk time by $7 \%$ (from $54 \%$ to $58 \%$ of the total talk time; $P<.001$ ), robustly increased the number and duration of "change talk" segments by $639 \%$ (from 0.54 to 3.45 times per visit; $P=.0007$ ), increased the number of patient cut-ins by $237 \%$ (from 3.72 to 8.81 times per visit; $P=.04$ ), and tended to increase the number and duration of 
clinician "advice talk" (from 1.10 to 2.45 times per visit; $P=.065$ ). The total number, duration, and proportions of conversation turn types (initiations, questions, responses, and rapid exchanges), and some of the talk types-including goal-setting talk, education talk, and prescriptive talk-did not change.

The majority of patients and clinicians had a positive experience with "primed" AWVs. Patients felt more informed, empowered, and motivated by the wellness visit when previsit components (supportive technology and HRA report, framing of the patient and clinician visit, education, and conversation-strengthening resources) were in place. Clinicians emphasized that the HRA report helped them construct and follow a systematic visit agenda more effectively and that it facilitated the convergence of patient goals with evidence-based health recommendations suggested by the HRA report. The HRA report displayed global health scores, estimates for life and health expectancy, and a personalized list of health strengths and challenges, in addition to prioritized health improvement recommendations. A "RealAge" estimate and a wellness score displayed using color-coded gauges were particularly helpful to patients, allowing them to visualize their current health status and how their choices may affect long-term health outcomes. The following quotes represent general sentiments about the AWV process. One patient reflected on discussing her health report during the visit: "Wow ... I had no idea that smoking has such a big effect on my health!" Another patient noted: "We talked about a lot of things that we would not have before." A third patient added: "[The visit] helped me make my bealth a priority and organize my thoughts about my bealth." Others expressed that the AWV reaffirmed what they already knew, but in a more interesting and motivating way, while a few patients felt that the health scores and estimates were less favorable than how they perceived their health status, which prompted additional conversation with the clinician. A patient noted that the doctor "always goes over this stuff with me, but seeing my RealAge and my numbers was helpful! We talked about my health in a different way."

\section{Discussion}

Our pilot study suggests that more work needs to be done to realize the potential of AWVs and enable patients and clinicians to maximize the value of HRA-based health planning. It also suggests that simply inserting an HRA into a patient visit may not improve shared decision making, goal setting, and unhealthy behaviors. Furthermore, the results indicate that strategically implemented, feasible interventions may significantly improve at least some aspects of health conversations between patients and clinicians.

This pilot study was part of an academic research program for medical students that aimed at immersing them into meaningful family medicine research and kindling in them a passion for the profession. Our study implemented a quasi-experimental design, and our timeline and scope were limited. However, we took methodological rigor seriously and ensured that differences in known covariates were minimized by comparing matched pre- and post-intervention AWVs. Although our findings need to be confirmed by a more definitive study, robust effect sizes (about 2.5 to 6.5 times the baseline) that were developed over a 30 -day intervention following a 3-month baseline period suggest that a relatively low-intensity, multicomponent intervention may effectively improve HRAbased health conversations.

Our past research aimed to develop a 3-step, goal-directed care delivery model $\mathrm{l}^{3,9,10}$ that includes patient and practice preparation for wellness visits ("ready" step), HRA-based goal setting and health planning during wellness visits ("set" step) and systematic follow-up to support goal attainment ("go" step). Although we have learned much from these studies about the first and third steps, our understanding remained limited about the conversation that occurred when the HRA report was introduced and how these conversations could be improved. The current study enables us to develop our care model further by introducing appropriate patient and clinician education, resources to support decision making, and supportive technology that are feasible to implement in real-world practices.

Despite a considerable improvement of change talk and favorable shifts in health conversation dynamics, our intervention did not improve goalsetting conversations. This might be related to a relative increase in time spent by clinicians in advice talk in the intervention group, which could have competed with time available for listening and encouraging patients to set their own goals, one of the practical techniques in MI. ${ }^{11}$ Given the limited 
scope and time of our intervention, and that helping patients set SMART goals may require the most time and skilled effort, it is reasonable to suggest that further adjustments in the intensity and content of our intervention may enhance goalsetting conversations as well. These adjustments may include additional emphasis on patient empowerment for goal setting through patient and clinician education and direct feedback to clinicians regarding selected visits observed by a professional trained in MI and goal setting. These approaches have been used successfully in family medicine resident education to boost health conversation skills. Our analyses did not measure the occurrence and potential shifts in "sustain talk," which can be conceptualized as a part of change talk that allows the parties to explore obstacles toward change. ${ }^{12}$ This is a more nuanced conversational element in MI that our pilot study was not sufficiently powered to explore.

Our study also underscored that regular wellness visits (even when the full 30-minute time is available) are usually limited to addressing specific health challenges and that clinicians often struggle to keep the visit focused on health planning, which has clinical and financial consequences (eg, missing important opportunities for improving health or increasing the patient's out-of-pocket costs by providing or ordering extra services). In this context, it was important that our advanced HRA could present tailored preventive service recommendations that were also prioritized based on their estimated impact on health outcomes (eg, length of life). This allowed patients and clinicians to put competing needs into context and help streamline the visit agenda.

While ubiquitous patient-facing technologies are being used increasingly, especially in specific populations, ${ }^{13}$ older individuals with a higher disease burden and those in with a lower socioeconomic status may rely more on practice-bound approaches to contribute health information (eg, waiting room surveys). It may be challenging for practices to implement informative health assessments because HRAs may add considerable time to visits when completed in the practice, and they may require additional patient support. On the other hand, Web-based HRAs and other electronic health tools that can inform care "remotely" may also be challenging to deploy because of privacy requirements that necessitate the use of secure on- line accounts. Completing HRAs in the practice may help alleviate account access problems, but it may also ineffectively shift the burden of collecting patient-reported data to practices without providing additional support. The legal framework for sharing patient data through electronic health technologies is underdeveloped, and even when data are exchanged, patient-reported information may not always guide decision making because of the lack of data integration.

Proper framing of AWVs emerged as a pivotally important factor. Patients have been "conditioned" by the health care system to be reactive and problem-focused, and it may take a conceptual shift for health care teams to implement effective health planning that does not fit well into regular office visits. In this study we opted to implement patient call scripts that we derived from exemplars to orient patients to AWVs, and similar conversations occurred with clinicians. Despite these efforts, some AWVs indicated a continuing struggle with integrating health planning into the usual care delivery approach.

\section{Conclusions}

Our study suggests that HRAs introduced without proper framing, education, and additional resources may not allow patients and clinicians to optimally leverage AWVs for health planning and improvement. A low-intensity, multicomponent intervention may help patients and clinicians improve the quality of HRA-supported health conversations and realize the potential of AWVs. Although more research is needed to find an optimal intensity and combination of clinician- and patient-facing interventions, our study suggests that even limited investments into improving interactions during AWVs may facilitate effective health improvement in primary care settings.

The authors appreciate the enthusiasm and generous contributions of University of Oklahoma Department of Family Medicine faculty and their patients, who participated in this study. They also appreciate the support of the Family Medicine Summer Research Experience program that allowed medical students and graduates to participate in meaningful, front-line health care research.

To see this article online, please go to: http://jabfm.org/content/ 30/2/161.full. 


\section{References}

1. Hughes C. What you need to know about the Medicare preventive services expansion. Fam Pract Manag 2011;18:22-5.

2. Hughes C. Medicare annual wellness visits: don't forget the health risk assessment. Fam Pract Manag 2012;19:11-4.

3. Nagykaldi ZJ, Voncken-Brewster V, Aspy CB, Mold JW. Novel computerized health risk appraisal may improve longitudinal health and wellness in primary care: a pilot study. Appl Clin Inform 2013;4:75-87.

4. Connecticut Children's Medical Center. Nutrition resources. Resources for physicians: motivational interviewing (MI). Available from: http://www.connecticutchildrens.org/our-care/nutrition/resources. Accessed June 15, 2016.

5. Jansen KL, Rosenbaum ME. The state of communication education in family medicine residencies. Fam Med 2016;48:445-51.

6. Pomerantz A, Fehr BJ. Conversation analysis: an approach to the study of social action as sense making practices. In: van Dijk TA, ed. Discourse as social interaction. Discourse studies 2: a multidisciplinary introduction. Thousand Oaks, CA: Sage Publications; 1997. pp. 64-91.
7. Cohen DJ, Clark EC, Lawson PJ, Casucci BA, Flocke SA. Identifying teachable moments for health behavior counseling in primary care. Patient Educ Couns 2011;85:e8-15.

8. Doran GT. There's a S.M.A.R.T. way to write management's goals and objectives. Manage Rev 1981; $70: 35-6$.

9. Nagykaldi Z, Aspy CB, Chou A, Mold JW. Impact of a wellness portal on the delivery of patientcentered preventive care. J Am Board Fam Med 2012;25:158-67.

10. Nagykaldi ZJ, Jordan M, Quitoriano J, Ciro CA, Mold JW. User-centered design and usability testing of an innovative health-related quality of life module. Appl Clin Inform 2014;5:958-70.

11. Purath J, Keck A, Fitzgerald CE. Motivational interviewing for older adults in primary care: a systematic review. Geriatr Nurs 2014;35:219-24.

12. Miller WR, Rollnick S. Motivational interviewing: helping people change. 3rd ed. New York: Guilford; 2013.

13. 2015 HIMSS Mobile Technology Survey. Chicago: Healthcare Information and Management Systems Society; 2017. Available from: http://www.himss. org/2015-mobile-survey. Accessed June 15, 2016. 